\title{
BMJ Open Burnout in consultants in child and adolescent mental health services (CAMHS) in Ireland: a cross- sectional study
}

Fiona McNicholas (D) , ${ }^{1,2,3}$ Sonita Sharma, ${ }^{1}$ Cliodhna Oconnor, ${ }^{1}$ Elizabeth Barrett ${ }^{1,4}$

To cite: McNicholas F, Sharma S, Oconnor C, et al. Burnout in consultants in child and adolescent mental health services (CAMHS) in Ireland: a cross-sectional study. BMJ Open 2020;10:e030354. doi:10.1136/ bmjopen-2019-030354

- Prepublication history for this paper is available online. To view these files, please visit the journal online (http://dx.doi. org/10.1136/bmjopen-2019030354).

Received 09 April 2019 Revised 20 November 2019 Accepted 22 November 2019

Check for updates

(c) Author(s) (or their employer(s)) 2020. Re-use permitted under CC BY-NC. No commercial re-use. See rights and permissions. Published by BMJ.

${ }^{1}$ School of Medicine and Medical Science, University College Dublin, Dublin, Ireland

${ }^{2}$ Lucena Clinic, St John of God, Dublin, Ireland

${ }^{3}$ Our Lady's Hospital for Sick Children, Dublin, Ireland ${ }^{4}$ Temple Street University Hospital, Dublin, Ireland

Correspondence to Professor Fiona McNicholas; fionamcn2008@gmail.com

\section{ABSTRACT}

Physician burnout has reached epidemic levels in many countries, contributing to adverse personal, patient and service outcomes. Adverse socioeconomic conditions, such as the economic downturn in the Ireland post 2008, contribute to a situation of increased demand but inadequate resources. Given a recent unprecedented increase in referrals to Irish child and adolescent mental health services (CAMHS), coupled with a fragmented and poorly resourced service, it is important to reflect on consultant child psychiatrists' well-being.

Objectives To report on the level of burnout among consultants working in CAMHS in Ireland using a crosssectional design.

Setting Community CAMHS in Ireland.

Participants An online questionnaire was sent to all consultant child psychiatrists registered with the Irish Medical Council ( $n=112$ ). Fifty-two consultants replied (46\% response rate).

Primary outcome measures Questions assessed demographic and occupational details, career satisfaction and perceived management, government and public support. The Copenhagen Burnout Inventory measured personal, work and patient-related burnout.

Results The prevalence of moderate or higher levels of work-related and personal burnout was $75 \%$ and $72.3 \%$, respectively. Fewer ( $n=14,26.9 \%)$ experienced patientrelated burnout. There was a strong correlation between work burnout and personal $(r=0.851, n=52, p<0.001)$ and patient-related burnout $(r=0.476, n=52, p<0.001)$. Lack of confidence in government commitment to investment in CAMHS $(p<0.001)$ and perceived ineffective management by health authorities $(p=0.002)$ were associated with higher burnout scores. Few consultants $(n=11,21 \%)$ felt valued in their job. The majority $(n=36,69 \%)$ had seriously considered changing jobs, and this was positively associated with higher burnout $(p<0.001)$. Higher burnout scores were present in those $(n=15,28.8 \%)$ who would not retrain in child psychiatry $(p=0.002)$.

Conclusion The high level of burnout reported by respondents in this study, and ambivalence about child psychiatry as a career choice has huge professional and service implications. Urgent organisational intervention to support consultant psychiatrists' well-being is required.
Strengths and limitations of this study

- Use of a validated instrument to measure personal, work and patient-related burnout.

- Relevance of the study to the current staffing and resources crisis in child and adolescent mental health services in Ireland.

- Low response rate $(46 \%)$.

- Cross-sectional design does not allow causality to be inferred.

- Risk of responder recall bias due to self-report nature of the survey.

\section{BACKGROUND}

Occupational stress is among the most prevalent work-related illnesses reported by workers in the European Union (EU), with significant personal and societal costs. ${ }^{1}$ In the Ireland, the most recent data available show that in $2015,18 \%$ of the Irish workforce experienced work-related stress. ${ }^{2}$ Although less than the European average, rates of occupational stress more than doubled between 2001 and 2015, with workers in Ireland experiencing the steepest increase compared with workers in other Western European countries. ${ }^{23}$

Burnout (BO) is a term used to describe long-term, unresolved, work-related stress, with feelings of physical and emotional exhaustion, depersonalisation and a reduced sense of personal accomplishment as central features. ${ }^{4}$ In this context, $\mathrm{BO}$ is thought to occur when demand exceeds capability or availability. In conditions where there is increased demand but reduced or inadequate resources, this imbalance will be most evident, presenting a ripe breeding ground for occupation stress. Such a scenario is familiar to many working in health services: a recent study of the Irish workforce shows those working in the health sector reported the highest rates of $\mathrm{BO} .{ }^{2}$ High $\mathrm{BO}$ rates among doctors is a very worrying statistic, given the 
implications for patient safety and service delivery. ${ }^{5}$ High BO rates have also been described in other clinical ${ }^{67}$ and non-clinical ${ }^{8}$ groups.

Currently in the Irish healthcare context, as with many other EU countries, it is recognised that demand far exceeds provision, leading to long waiting lists in many specialities and many doctors working in excess of European Working Time Directive requirement. ${ }^{9}$ In a recent survey of hospital doctors in Ireland $(\mathrm{n}=1749,55 \%$ response rate), $82 \%$ reported significant workplace stress, with one in three doctors reporting BO. ${ }^{9}$ This seems to be particularly relevant for mental health services: the proportion of the Irish health budget devoted to mental health has decreased since 2008 and currently stands at $6 \%$, lower than in many other countries. ${ }^{10}$ An even smaller percentage goes to child and adolescent mental health services (CAMHS), which remains neglected, despite a surge in referral rates (up 26\% from 2012) and recognition of CAMHS staffing being well below recommendations. ${ }^{11}$

In addition to reduced funding, consultants working in psychiatry may be a particularly vulnerable group, as they are exposed to and expected to manage stress from numerous sources. ${ }^{12}$ They must be able to manage their own stress levels, support their teams and treat stress and mental illness in their patients. Although not unique to psychiatry, compassion fatigue, negative transference and vicarious traumatisation have been implicated in increased risk of $\mathrm{BO} .{ }^{12}$ Given the unprecedented increase in referrals to CAMHS, coupled with a fragmented and poorly resourced service, it is important to reflect on consultant child psychiatrists' well-being. This imbalance between shrinking resources and increasing demand in a specialty where clinician compassion and leadership is key led us to examine BO levels in consultants leading CAMHS teams. To date, no study has investigated $\mathrm{BO}$ in this specific population.

\section{OBJECTIVES}

This study aimed to report on the prevalence of $\mathrm{BO}$ among consultant psychiatrists working in CAMHS in Ireland using a cross-sectional design.

\section{METHOD}

Following ethics exemption, a survey was designed using the SurveyMonkey platform. A survey invitation and link was sent by the College of Psychiatry, Ireland (CPI) to all consultant child and adolescent psychiatrists who were registered with the Irish Medical Council, and members of the CPI $(n=112)$. Participants were invited to complete the questionnaire, which took approximately $10-15 \mathrm{~min}$. For ease of completion, responses to questions used a Likert Response Scale, respondents rating their level of agreement from always/often/sometimes/seldom/never. Two reminder follow-up emails were sent at 3 monthly intervals (May-August 2017). All responses were anonymised.
The strengthening the reporting of observational studies in epidemiology cross-sectional checklist was used when writing the report. ${ }^{13}$

\section{Patient and public involvement}

The focus of this study was on consultant stress levels. Although there was no direct involvement of patients or the public, the CPI assisted in the design and delivery of the study. They also sent the questionnaire directly to participants, collected and anonymised the responses, ensuring data privacy.

\section{Study questionnaire}

The study-specific questionnaire included basic questions on demographic details such as years in practice, work setting and team staffing levels. Questions assessed consultants' confidence in the public healthcare system, managed by the Health Service Executive (HSE) and funded by the government. Participants were also asked about public perception of CAMHS and satisfaction with their chosen career. To minimise identification, minimal personal data, such as age or gender, were collected.

A well-validated $\mathrm{BO}$ questionnaire, the Copenhagen Burnout Inventory (CBI) ${ }_{14}^{14}$ was used. This scale allows an examination of the level of personal stress or $\mathrm{BO}$, along with the degree of $\mathrm{BO}$ that is perceived to be related to work and client/patient population. Scores fall along three domains: work-related BO (seven questions), personal BO (six questions) and patient-related BO (six questions). The CBI has been found to predict future sick leave, relevant to work settings, and correlates well with other frequently used scales. ${ }^{15}$ All 19 questions are scored using a 5-point Likert Scale; 12 items have frequency responses (always/often/sometimes/seldom/never) and seven items intensity responses (ranging from 'a very low degree' to 'a very high degree'). All responses are positively skewed. Scores of 50-74 are considered moderate levels of BO, 75-99 high and 100 severe BO. ${ }^{15}$ The CBI has good psychometric properties. ${ }^{14} 16$ In the current study, there was high internal reliability as evidenced by high Cronbach alphas coefficients (work-related $\mathrm{BO} \alpha=0.942$, personal $\mathrm{BO} \alpha=0.874$ and patient-related $\mathrm{BO} \alpha=0.833$ ).

\section{Analysis}

For the purpose of analysis, Likert scales were considered as interval data. Kolmogorov-Smirnov tests confirmed normality for total and subscale CBI scores and hence parametric analysis was carried out. Descriptive data were calculated for each of the subscales, along with the proportion of respondents scoring moderate or higher levels of BO. Relationships between the subscales were evaluated using Pearson correlation coefficients. Mean CBI scores were compared with other binary variables using t-tests. Participants were divided into groups based on responses to (1) having considered changing jobs in the last year ('never' or 'rarely'/'sometimes'/'yes, definitely'), and (2) whether they would retrain in child psychiatry (no/ maybe/yes). One-way analysis of variance (ANOVA) was 
Table 1 Professional characteristics

\section{Total sample}

\begin{tabular}{|c|c|}
\hline Work place setting: $n=49$ & $\begin{array}{l}\text { CAMHS OPD; } n=42,81 \% \\
\text { CAMHS inpatient: } n=7,13 \%\end{array}$ \\
\hline Clinical years' experience: $n=52$ & $\begin{array}{l}\text { Mean } 14.5 \text { years, median }=13.0, S D=6.233 \text {, range } 1-30 \\
\text { years }\end{array}$ \\
\hline $\begin{array}{l}\text { Based on National MH Strategy Document, A Vision for Change, } \\
\text { what percentage (\%) resourcing is your consultant service? } n=44\end{array}$ & Mean $=51.94 \%$, median $=50 \%, S D=19.136$ \\
\hline $\begin{array}{l}\text { Have you or your organisation approached the HSE for more } \\
\text { funding or resources (in the last } 2 \text { years)? } n=52\end{array}$ & $\begin{array}{l}\text { Yes, } n=47,90.4 \% \\
\text { No, } n=5,9.6 \%\end{array}$ \\
\hline $\begin{array}{l}\text { Have you or your organisation advocated publically for more } \\
\text { funding or resources? } n=50\end{array}$ & $\begin{array}{l}\text { Yes, } n=10,10 \% \\
\text { No, } n=40,80 \%\end{array}$ \\
\hline $\begin{array}{l}\text { What percentage of your week do you think you spend on what } \\
\text { you consider to be outside of your area of responsibility, or 'not } \\
\text { core' responsibility of CAMHS? } n=52\end{array}$ & Mean=3.8, median=4 (20\%-30\%), SD=3.83 \\
\hline
\end{tabular}

' $n$ ' represents the numbers who answered each question.

CAMHS, child and adolescent mental health services; HSE, Health Service Executive; MH, mental health; OPD, Out Patients' Department.

used to compare mean CBI scores across these dimensions. There were minimal missing sociodemographic and study-specific questionnaire data; the number of respondents for each variable is represented in each table by ' $n$ '. All respondents completed the CBI in full.

\section{RESULTS}

\section{Sample profile}

Fifty-two consultant child and adolescent psychiatrists replied (46\% response rate). Forty-nine participants provided their specialty, with the majority $(n=42,81 \%)$ working in CAMHS outpatient community settings (table 1). A smaller number $(n=7,13 \%)$ worked exclusively in an inpatient setting (five in a specialist CAMHS inpatient unit and two in a paediatric hospital). Three did not indicate their work environment. Respondents $(n=51,98 \%)$ were, in general, seasoned clinicians with on average 14.5 years as a consultant (range $1-30$ years).

\section{Working conditions}

Forty-four (84.6\%) consultants responded to a question evaluating their service based on the Irish national mental health strategy document, a Vision for Change, which sets out the direction and staffing planning for mental health services in Ireland. ${ }^{17}$ Twenty-seven $(61 \%)$ were staffed at $50 \%$ or less of the recommended levels. Although two respondents (one each from an outpatient and inpatient setting) reported full staffing levels, nine $(20.5 \%)$ had levels of staffing $30 \%$ below recommended levels. The majority of consultants $(n=37,90 \%)$ had sought additional funding directly from the HSE and a smaller number $(n=10,19 \%)$ had advocated publically for such funding (table 1). Consultants were also asked what percentage of their time they spent on work considered outside of their area of responsibility or non-core work. The median value was $30 \%$, with a range from $0 \%(\mathrm{n}=5$, $15.5 \%)$ to more than half of their time $(n=5,15.5 \%)$.

\section{Work satisfaction}

The majority of respondents had seriously considered changing jobs $(n=36,69 \%)$. Almost a third $(n=15,29 \%)$ would not choose child psychiatry again as a specialty if retraining, with a further $18(36 \%)$ undecided (table 2 ). Few consultants felt valued in their job, almost half stating this was 'rarely or never' their experience $(n=21,40 \%)$. A similar number believed staff on their teams rarely or ever experienced job satisfaction $(n=19,37 \%)$. The majority believed that their workload $(n=46,88 \%)$ or degree of job satisfaction $(n=29,57 \%)$ interfered (often or always) with their ability to engage in new initiatives, training or academic work.

\section{Perceived management, government and public support}

Consultants were asked about the HSE and the government's commitment to planning and investing in child psychiatry (table 2). Although the majority of respondents had in fact sought (although not necessarily received) additional funding in the previous 2 years $(\mathrm{n}=37,90 \%)$, the majority $(\mathrm{n}=38,73 \%)$ believed commitment to investment was 'never or rarely' present. They also expressed low confidence in the ability of the recent Seanad Committee (senate of Ireland) hearing on mental health $^{18}$ to have a meaningful impact on their lives as clinicians $(n=12,25 \%)$ or those of their patients $(n=15$, $31 \%$ ). Only one respondent felt the government was serious about a commitment to children's mental health or effectively planning services. There was a general sense of cynicism regarding the ability of political involvement to make meaningful change $(n=19,39 \%)$. Consultants feared minimal change in public opinion towards CAMHS in recent years $(n=31,60 \%$ stated no or minimal change) and one-third perceived the public to have very unrealistic expectations about what CAMHS could or should deliver $(n=17,33 \%)$. Participants also felt that, when compared with other medical specialities, CAMHS 


\begin{tabular}{|c|c|c|c|c|c|}
\hline & $\begin{array}{l}\text { Always or to } \\
\text { a very high } \\
\text { degree }\end{array}$ & $\begin{array}{l}\text { Often or to a } \\
\text { high degree }\end{array}$ & $\begin{array}{l}\text { Sometimes/ } \\
\text { somewhat }\end{array}$ & $\begin{array}{l}\text { Seldom or to a } \\
\text { low degree }\end{array}$ & $\begin{array}{l}\text { Never } \\
\text { or to a very } \\
\text { low degree }\end{array}$ \\
\hline $\begin{array}{l}\text { Have you seriously thought of changing jobs in the last } \\
6-12 \text { months? } n=52\end{array}$ & 17 (33\%) & 19 (37\%) & $8(15 \%)$ & $2(4 \%)$ & $6(11 \%)$ \\
\hline $\begin{array}{l}\text { If you were training again, would you choose child } \\
\text { psychiatry as a specialty? } n=51\end{array}$ & $\begin{array}{l}\text { Yes } \\
18(35 \%)\end{array}$ & & $\begin{array}{l}\text { Not sure } \\
18(36 \%)\end{array}$ & & $\begin{array}{l}\text { No } \\
15(29 \%)\end{array}$ \\
\hline $\begin{array}{l}\text { Does your current level of job satisfaction interfere with } \\
\text { your interest in developing new initiatives or contributing } \\
\text { to training and academic work? } n=51\end{array}$ & $14(27 \%)$ & 15 (30\%) & 12 (24\%) & $6(11 \%)$ & $4(8 \%)$ \\
\hline $\begin{array}{l}\text { Does your current workload interfere with your ability } \\
\text { to develop new initiatives or contribute to training and } \\
\text { academic work? } n=52\end{array}$ & 24 (46\%) & $22(42 \%)$ & $3(6 \%)$ & $1(2 \%)$ & $2(4 \%)$ \\
\hline $\begin{array}{l}\text { Do you feel that the HSE is effectively planning } \\
\text { improvements in CAMHS? } n=52\end{array}$ & $1(2 \%)$ & $3(6 \%)$ & $11(21 \%)$ & $21(40 \%)$ & 16 (31\%) \\
\hline $\begin{array}{l}\text { Do you believe that public opinion towards CAMHS has } \\
\text { improved in recent years? } n=52\end{array}$ & $1(2 \%)$ & 0 & 20 (39\%) & 20 (39\%) & $11(21 \%)$ \\
\hline $\begin{array}{l}\text { Do you feel that the public have unrealistic expectations } \\
\text { of what CAMHS can provide? } n=52\end{array}$ & $2(4 \%)$ & 15 (29\%) & $22(42 \%)$ & 12 (23\%) & $1(2 \%)$ \\
\hline $\begin{array}{l}\text { Do you think the manpower and public perception } \\
\text { experiences within CAMHS are just as favourable/ } \\
\text { unfavourable as other specialities of medicine? } n=50\end{array}$ & \multicolumn{5}{|c|}{$\begin{array}{l}\text { As favourable } n=2(3.8 \%) \\
\text { Not as favourable } n=40(76.9 \%) \\
\text { Not sure } n=2(3.8 \%)\end{array}$} \\
\hline $\begin{array}{l}\text { Do you think the recent Seanad Public Consultation } \\
\text { Committee will lead to any meaningful changes in the } \\
\text { lives of clinicians providing CAMHS? } n=48\end{array}$ & \multicolumn{5}{|c|}{$\begin{array}{l}\text { Yes } n=0 \\
\text { No } n=12(25 \%) \\
\text { Maybe } n=9(18 \%) \\
\text { Cynical about politics } n=28(57 \%)\end{array}$} \\
\hline
\end{tabular}

CAMHS, child and adolescent mental health services; HSE, Health Service Executive; $M H$, mental health.

was viewed less favourably by the public and was less well resourced $(n=40,77 \%)$.

\section{Burnout}

Fifty-two respondents completed all questions on the CBI. The overall prevalence of respondents reporting moderate degrees of $\mathrm{BO}$ or higher was $59.6 \%$ (table 3 ). Rates varied between the CBI subdomains, with very high levels being reported in both work and personal domains. Thirty-nine $(75 \%)$ experienced moderate or higher levels of work-related $\mathrm{BO}$, and 35 (72.3\%) consultants experienced moderate or higher levels of personal BO. Three consultants $(5.8 \%)$ rated their level of personal $\mathrm{BO}$ as severe. The overall prevalence of patient-related $\mathrm{BO}$ was much lower, with 14 (26.9\%) experiencing moderate or higher levels of work-related BO. The majority $(n=38$, $73 \%$ ) reported no or minimal patient-related BO.

There was a strong positive correlation between all CBI subscales, strongest for work and personal $\mathrm{BO}, r=0.851$, $\mathrm{n}=52, \mathrm{p}<0.001$. High levels of work-related $\mathrm{BO}$ were also associated with high patient-related $\mathrm{BO}, r=0.476, \mathrm{n}=52$, $\mathrm{p}<0.001$. Although there was a significant association with personal and patient-related $\mathrm{BO}$, this was not as strong, $r=0.322, \mathrm{n}=52, \mathrm{p}=0.02$. Using the coefficient of determination, work-related $\mathrm{BO}$ helped explain $72.4 \%$ of the variance on the personal subscale and $22.7 \%$ of the variance on the patient $\mathrm{BO}$ scale, while the shared variance between personal and patient BO was only $10.3 \%$ (table 4).

An independent t-test was used to compare the total BO scores for clinicians working in CAMHS outpatient settings as compared with an inpatient setting. There was no significant difference in mean BO scores between outpatient and inpatient consultants. Although mean BO scores were higher in those with fewer resources, this was not significant (table 5). However, significantly higher BO scores were found in those who lacked confidence in the HSE's ability to effectively manage services and the degree of government commitment to CAMHS (table 5).

A one way between group ANOVA identified a significant relationship between $\mathrm{BO}$ and consultants' consideration 
Table 3 Scores, cut-offs and reliability of the Copenhagen Burnout Inventory (CBI)

\begin{tabular}{|c|c|c|c|}
\hline CBI & M (SD) & $\begin{array}{l}\text { Prevalence cut-off } \\
\text { N (\%) }\end{array}$ & Cronbach alpha \\
\hline Work-related burnout $n=52$ & $59.41(19.63)$ & $\begin{array}{l}\text { No/low }(<50)=13(25 \%) \\
\text { Moderate }(50-74)=28(53.8 \%) \\
\text { High }(75-99)=10(19.2 \%) \\
\text { Severe }(100)=1(1.9 \%)\end{array}$ & 0.942 \\
\hline Personal burnout $n=52$ & $55.93(24.0)$ & $\begin{array}{l}\text { No/low }(<50)=17(32.7 \%) \\
\text { Moderate }(50-74)=22(42.3 \%) \\
\text { High }(75-99)=10(19.2 \%) \\
\text { Severe }(100)=3(5.8 \%)\end{array}$ & 0.874 \\
\hline Patient-related burnout $n=52$ & $38.2(16.01)$ & $\begin{array}{l}\text { No/low }(<50)=38(73 \%) \\
\text { Moderate }(50-74)=13(25 \%) \\
\text { High }(75-99)=1(1.9 \%) \\
\text { Severe }(100)=0\end{array}$ & 0.833 \\
\hline
\end{tabular}

of changing jobs, $F(2,49)=12.198, \mathrm{p} \leq 0.001, \eta^{2}=0.332$. Post hoc comparisons using Tukey's HSD test indicated that the mean $\mathrm{BO}$ score for those who had not/rarely wished to change jobs was significantly lower $(\mathrm{M}=30.263$, $\mathrm{SD}=15.85)$ than those who responded 'sometimes' $(\mathrm{M}=47.862, \mathrm{SD}=14.60)$ or 'yes, definitely' $(\mathrm{M}=57.20$, $\mathrm{SD}=16.972$ ). There was no significant difference between the latter two groups. Similarly, an ANOVA revealed significant BO differences between those who would and would not consider retraining in child psychiatry, $F$ (3, $47)=7.359, \mathrm{p}=0.002, \eta^{2}==0.264$. Post hoc comparisons indicated that the mean $\mathrm{BO}$ score for those who would not retrain in child psychiatry $(\mathrm{M}=59.04, \mathrm{SD}=17.13)$ or were undecided $(\mathrm{M}=58.49, \mathrm{SD}=9.14)$ was significantly higher than the no group $(\mathrm{M}=40.64, \mathrm{SD}=16.86)$.

\section{DISCUSSION}

Fifty-two consultant child and adolescents psychiatrists responded to this survey with the majority $(59.6 \%)$ reporting moderate or higher levels of $\mathrm{BO}$, as measured by the CBI. Both work-related and personal BO levels were high, with $75 \%$ and $72.3 \%$ scoring in the moderate or higher levels, respectively. The corresponding means (work related $=59.41$, personal $=55.93$ ) are much higher

Table 4 Pearson product-moment correlations between burnout domains

\begin{tabular}{llll}
\hline Scale & 1 & 2 & 3 \\
Total burnout score & 1 & & \\
Personal & $0.905^{\star}$ & 1 & \\
Work & $0.948^{*}$ & $0.851^{*}$ & 1 \\
Patient & $0.644^{*}$ & $0.322 \dagger$ & $0.476^{\star}$ \\
\hline
\end{tabular}

${ }^{*}$ Correlation is significant at the 0.01 level (two tailed).

†Correlation is significant at the 0.05 level (two tailed). than the referenced norms. ${ }^{19}$ In a large $(n=1914)$ Danish prospective study, which recruited participants from seven different types of work (including hospital employees), mean work-related BO $(\mathrm{M}=33.0)$ and personal BO $(\mathrm{M}=35.9)$ were much lower than values found in this study. ${ }^{19}$ More recent studies using the CBI allow a direct comparison with other clinical groups. In a sample of almost 1500 senior doctors and dentists in New Zealand, their reported rates of $\mathrm{BO}$ were lower, with corresponding prevalence rates of $42.1 \%$ and $50.1 \% .^{20}$ In a sample of 1037 Australian midwives, equivalent prevalence rates were also much lower $(43.8 \%$ for work-related BO and $64.9 \%$ for personal) than that found among child psychiatry consultants practicing in Ireland. ${ }^{21}$ Two other studies examining doctors working in Irish hospitals reported rates of $\mathrm{BO}$ considered by the authors to be higher than their European colleagues, with junior doctors being most at risk. ${ }^{92}$

There is some evidence to suggest that $\mathrm{BO}$ is further elevated in the specialty of psychiatry and among trainees. A recent systematic review concluded that psychiatrists, particularly woman and those in training, suffered from higher levels of $\mathrm{BO}$ and psychological distress than other medical groups. ${ }^{23}$ Hayes et al found that younger age, higher effort-reward imbalance and overcommitment were associated with higher BO rates among Irish hospital doctors. ${ }^{9}$ The 'BOSS' study, which was a large international study on BO $(n=1980)$ and included both psychiatrists and trainees, found $39 \%$ of their sample reported severe $\mathrm{BO}$, high levels of depression and suicidal thinking. In fact, among the Irish trainees recruited in the BOSS study, although their rate of depression was lower than their peers $(10 \%$ vs $16 \%$, using the Patient Health Questionnaire-9), stressful working conditions and lack of supervision contributed to their higher BO scores. ${ }^{24}$ Although age and gender were not collected in our study, to help protect respondent identity, there was no 


\begin{tabular}{|c|c|c|c|c|c|}
\hline Variable & $\mathbf{n}$ & Mean burnout & SD & $\mathbf{t}$ & $P$ value \\
\hline \multicolumn{6}{|c|}{ CAMHS setting } \\
\hline Outpatient & 39 & 52.5641 & 17.64271 & -0.891 & 0.378 \\
\hline Inpatient & 10 & 47.1053 & 15.72599 & & \\
\hline \multicolumn{6}{|c|}{ Degree of resourcing based on AVFC } \\
\hline$<50 \%$ & 27 & 53.2164 & 13.75823 & 0.798 & 0.430 \\
\hline$>50 \%$ & 17 & 49.1486 & 20.11664 & & \\
\hline \multicolumn{6}{|c|}{ Confidence in HSE management } \\
\hline No & 48 & 53.8651 & 13.75823 & 3.692 & 0.001 \\
\hline Yes & 4 & 24.6711 & 20.11664 & & \\
\hline \multicolumn{6}{|c|}{ Confidence in government commitment } \\
\hline No & 38 & 56.6482 & 13.75823 & 4.006 & $<0.001$ \\
\hline Yes & 14 & 37.9699 & 20.11664 & & \\
\hline
\end{tabular}

AVFC, A Vision For Change; CAMHS, child and adolescent mental health services; HSE, Health Service Executive.

association with years working as a consultant and stress levels, suggesting that in our study seniority and experience did not confer advantage.

There is some evidence in the literature of a higher rate of BO in clinicians working with children. Margiotta et al found that paediatricians in Ireland scored higher than other groups, ${ }^{22}$ and in a large Finnish study $(n=3313)$, while psychiatrists had a higher prevalence of BO than other specialities, the highest rates were found in those working in child psychiatry and in the community. ${ }^{25}$ Even when biological markers are used to measure 'stress', levels among nurses in a CAMHS inpatient setting were found to be higher than in a neonatal intensive unit. ${ }^{26}$

High rates of personal and work-related $\mathrm{BO}$ have been associated with more negative feelings towards patients ${ }^{12}$ and higher rates of cynicism. ${ }^{27}$ Although respondents in our study reported very high rates of $\mathrm{BO}$ in both work and personal domains, rates of patient-related $\mathrm{BO}$ was much lower. The majority $(\mathrm{n}=38,73 \%)$ reported no or minimum BO, suggesting an absence of compassion fatigue, and the majority continued to advocate for their patient group. However, given the therapeutic salience of the relationship psychiatrists have with their patients, and their need to be emotionally available and empathic, high personal or work-related stress may impede this. Maslach and Leiter emphasise that in addition to risks associated with lack of support from colleagues and management, contact with patients and families who present with psychological trauma, have unrealistic service expectations, and/or may be demanding or challenging, present unique challenges for the psychiatrist. ${ }^{12}$

There were ample evidence in our study of a sense of lack of support from both management (HSE) and government, cynicism about the possibility of change, coupled with unrealistic public expectations of CAMHS and a sense of a lack of parity of child psychiatry. These were all factors outside of the control of the consultant. In a qualitative study of Irish consultants, Walsh et al found that the top three concerns contributing to $\mathrm{BO}$, again extrinsic factors, were 'quick fix' management planning, staff shortages and inadequate resources. ${ }^{28}$

The issue of under-resourcing was also prominent in this study and most respondents indicated their services were understaffed based on A Vision for Change recommendations. ${ }^{17}$ Although $15 \%$ indicated that their staffing levels were at or above $75 \%$ recommended levels, most $(\mathrm{n}=22,50 \%)$ had services operating at 50\% staffing levels, with one service having only $20 \%$ of recommended resources. However, unlike in other studies, respondents operating with lower than recommended resourcing levels did not report higher BO levels. ${ }^{28}$ Certain perceptions rather than resourcing were associated with higher BO levels. These included not having confidence in either the HSE's ability to manage the services effectively $(\mathrm{n}=37,71 \%)$ or the government's commitment to invest $(\mathrm{n}=38,73 \%)$, also reflected in other research. ${ }^{28}$ These results resonate with the words of author and doctor, Rachel Clarke's in her book 'Your Life in My Hands', with reference to a 'a desperately overstretched workplace that breeds corner-cutting, indifference and excessive haste'. ${ }^{29}$ Tireless and dedicated service delivery, despite poor work conditions, as seen in this study, is a known response by care providers, as they prioritise the needs of others over their own, with the resultant risk of professional inefficacy, cynicism and personal $\mathrm{BO}$.

What is perhaps most alarming is that $65 \%$ of consultant in this study, if given the opportunity, had reservations about training in child psychiatry. Seventy per cent had seriously considered changing jobs in the last 6-12 months and this was significantly related with high levels of BO. Other studies have also reported that higher BO rates are linked with career choice dissatisfaction. ${ }^{24}$ This high rate of career ambivalence among consultant child psychiatrists is higher than rates in other specialities. ${ }^{9}$ This 
may contribute to understanding the current and unprecedented difficulty with staff recruitment and retention in CAMHS in Ireland, with recent media and government reference to large numbers of unfilled consultant child psychiatry posts, and many more filled with occupants not on the specialist register, raising serious concerns in relation to patient safety. ${ }^{30}$

The consequences of systematic failure to address medical under-resourcing have been recognised in the UK (Francis Report) ${ }^{31}$ and in Ireland (MacCraith Report), ${ }^{32}$ with parallel attempts to address these (MacCraith Working Group). However, progress has been slow in Ireland, where the negative impact of the 2008 financial crisis and the associated $30 \%$ pay reduction continue to have effect. Many of the recommendations made by the MacCraith report, especially around retention, have not been successful. ${ }^{33}$ Poorer working conditions, unequal remuneration and type of contract were found to adversely affect BO levels among consultants in Ireland, where a two tier consultant contract exists. ${ }^{22}$ Working conditions of hospital doctors in Ireland were also considered less favourable than in other EU countries. ${ }^{9}$

Current consultant psychiatry numbers (per 100 000) in Ireland are less than half the EU average, and a vicious cycle is perpetuated between under-resourcing, poor work conditions, high work stress, long waiting lists and unacceptable patient risk. Retention of existing staff and recruitment of new staff are a top priority, yet difficult to attain, with both Irish trained and non-EU trained doctors considering leaving. ${ }^{35}$ In our study, as with other studies, new entrants to consultant posts are already showing signs of high BO, with many newly trained doctors now choosing to emigrate. The Medical Council of Ireland Intelligence Report and the Royal College of Surgeons Ireland (RCSI) Health Workforce examined reasons for emigration among Irish medical graduates in 2015. They identified 'push' factors to include 'stressful conditions' compounded by low staffing and 'lack of designated and supervised training, ${ }^{36}{ }^{37}$ findings which have been echoed in other studies.$^{12} 28$ If clinical standards are to remain high, and children and families are to receive expert quality care, then urgent attention needs to be given to both work conditions and physicians' mental health.

If clinical standards are to remain high, and children and families are to receive expert quality care, then urgent attention needs to be given to both work conditions and physicians' mental health.

Retention and attracting newly qualified doctors into psychiatry are essential to ensure that we have the necessary manpower required. Such concerns are not unique to Ireland, and have been raised in the UK and in the USA. $^{3} 3839$ Psychiatry was found to be a less-favoured specialty by UK-trained graduates than other career choices $^{40}$; attitudes towards a career in psychiatry were more polarised than views about other specialties and graduates who initially chose psychiatry as a career did not stay. ${ }^{41}$ In addition to resources and working conditions, negative perceptions regarding the scientific nature of the specialty, effectiveness of interventions and public attitudes all increase the risk of trainee drift, some of which were apparent in our study.

Collectively these factors contribute to a worldwide concern that physician BO has reached epidemic levels, and that in particular psychiatrists risk becoming an 'endangered species'. ${ }^{4243}$ Given the reluctance of the consultants in our study to consider retraining, and the impact of $\mathrm{BO}$ on their ability to engage in training of junior staff, this is a real concern for child psychiatry in Ireland.

Recognising and reducing work and personal $\mathrm{BO}$ are now as much a public concern as lack of investment in services. The negative effects of physician ill-health are well recognised both for patient, service and themselves. ${ }^{39} 4344$ Doctors' well-being is integral to professionalism and central to patient care, and has been proposed as a central missing quality indicator. ${ }^{45}{ }^{46}$ A systems level response is necessary, given contributors to $\mathrm{BO}$ include personal, service and culture issues within healthcare organisations. ${ }^{47}$ All should be tackled in order to reduce physician $\mathrm{BO}$, as reported by a recent systematic review and meta-analysis. ${ }^{43}$

Long waiting lists are a particular problem facing CAMHS in Ireland, and require innovative solutions. One example associated with positive outcomes, both in physician $\mathrm{BO}$ and patient well-being, was the recruitment of medical assistants to help prepare, manage and triage referrals worthy of exploration within Irish CAMHS. ${ }^{48}$ Individually targeted approaches, such as personal engagement in mindfulness, small group discussions and stress reduction programme, have also been identified as being effective. ${ }^{43}$ Attendance at Schwartz rounds has been associated with a statistically significant improvement in well-being and resulted in positive changes in clinician practice, ${ }^{4950}$ and is currently being rolled out in Ireland. ${ }^{51}$ Balint groups, regular facilitated meetings with physicians, have long been known to improve physician well-being and protect against $\mathrm{BO} .{ }^{52}$ They allow for a safe and unpressured reflection on everyday clinical encounters and the relationship between doctor and patient, and the emotions it engenders. The CPI has now mandated participation of all trainees in Balint groups and support to attend such interventions, even on line, might well be considered for consultants. However, when asked, doctors opt for primary-level interventions aimed at bringing about system and cultural change, rather than focusing at the individual level. ${ }^{28}$ Avoiding ascribing blame to the clinician for being responsible for their own ill-health is paramount. A combination of individually targeted and system-wide interventions might be the most effective and sustainable approach.

\section{Strengths and limitations}

This is the first study examining levels of $\mathrm{BO}$ among consultant child and adolescent psychiatrists in Ireland, set against a background of unprecedented consultant vacancies and increasing CAMHS referrals. Although the 
response rate $(46 \%)$ was lower than hoped, it is comparable to that found in studies among consultants in Ireland $(42 \%-55 \%),{ }^{9}{ }^{22}$ studies within psychiatry $(26 \%)^{27}$ and studies using CBI $(22.5 \%-40 \%) .{ }^{20} 21$ It is unclear whether non-response would preferentially apply to busy overworked clinicians with high BO levels, too exhausted to participate, or if respondents are more likely to reflect those who had indeed experienced $\mathrm{BO}$ and wanted to have their voice heard. However, given there were no significant outliers, and the data were normally distributed, it is hoped that the results offer an informative insight into current $\mathrm{BO}$ levels in the target group.

Given the cross-sectional design and self-report nature of the survey, causality cannot be inferred and there is a risk of responder recall bias. The study used a validated instrument to measure personal, work and patient-related $\mathrm{BO}$, but minimal data were gathered on personal characteristics such as gender, age, marital status, thus limiting analysis on factors already known to be associated with higher BO rates. This was a necessary step, given the small sample size and the possibility of responder anonymity being lost.

\section{CONCLUSION}

Prevalence of personal and work-related $\mathrm{BO}$ among child and adolescent psychiatrists in Ireland is unacceptably high. Consultants are working with chronically understaffed teams, feel undervalued and have low levels of job satisfaction. They expressed significant ambivalence regarding remaining in post, retraining in the specialty, and a limited ability to contribute to academic work and training. Coupled with this is an external locus of control to effect change, with low confidence in either the HSE or the government, and a sense of unrealistic public expectations. These are worrying statistics and finding a solution is imperative. With the number of vacant consultant posts rising in both psychiatry and other medical professionals in Ireland and elsewhere, we need to heed the rising levels of work related and personal $\mathrm{BO}$ and implement change in order to ensure the well-being of our patients, professionals and indeed specialty, so that we do not become a 'speicis atá i mbaol' (Irish (Gaeilge) for endangered species).

Acknowledgements The authors express gratitude to all the consultants who completed the study and to the College of Psychiatry, Ireland for assistance with the study.

Contributors All contributors have meet at least of one the criteria recommended by the ICMJE. FM conceived and designed the study and wrote the first draft of manuscript. SS assisted with data analysis. SS, CO and EB contributed to subsequent drafts and revisions of paper.

Funding The authors have not declared a specific grant for this research from any funding agency in the public, commercial or not-for-profit sectors.

Competing interests None declared.

Patient consent for publication Not required.

Ethics approval This study received ethical exemption by chairman action OLCHC ethics committee. May 2017.

Provenance and peer review Not commissioned; externally peer reviewed.
Data availability statement Data are available upon reasonable request. The anonymous data set is held with the $\mathrm{PI}, \mathrm{FM}$. Any request to access the data should be made to fiona.mcnicholas@ucd.ie and will be considered.

Open access This is an open access article distributed in accordance with the Creative Commons Attribution Non Commercial (CC BY-NC 4.0) license, which permits others to distribute, remix, adapt, build upon this work non-commercially, and license their derivative works on different terms, provided the original work is properly cited, appropriate credit is given, any changes made indicated, and the use is non-commercial. See: http://creativecommons.org/licenses/by-nc/4.0/.

ORCID iD

Fiona McNicholas http://orcid.org/0000-0001-9428-6908

\section{REFERENCES}

1 Broughton A. Work-related stress [Internet]. Eurofound, 2010. Available: https://www.eurofound.europa.eu/sr/publications/report/ 2010/work-related-stress [Accessed 8 Oct 2019].

2 Russell H, Maitre B, Watson D. Job stress and working conditions: Ireland in comparative perspective. An analysis of the European working conditions survey. Esri.ie, 2018. Available: ://www.esri.ie/ system/files?file=media/file-uploads/2018-11/RS84.pdf [Accessed 8 Oct 2019].

3 Russell H, O'Connell PJ, McGinnity F. The impact of flexible working arrangements on work-life conflict and work pressure in Ireland. Gend Work Organ 2009;16:73-97.

4 World Health Organization. Burn-out an "occupational phenomenon": international classification of diseases, 2019. Available: https://www. who.int/mental health/evidence/burn-out/en/

5 Balch CM, Freischlag JA, Shanafelt TD. Stress and burnout among surgeons: understanding and managing the syndrome and avoiding the adverse consequences. Arch Surg 2009;144:371-6.

6 Gómez-Urquiza JL, Monsalve-Reyes CS, San Luis-Costas C, et al. [Risk factors and burnout levels in Primary Care nurses: A systematic review]. Aten Primaria 2017;49:77-85.

7 Dyrbye L, Shanafelt T, Sinsky C, et al. Burnout among health care professionals: A call to explore and address this under recognized threat to safe, high-quality care. NAM Perspectives, 2017. Available: https://nam.edu/burnout-among-health-care-professionals-a-callto-explore-and-address-this-underrecognized-threat-to-safe-highquality-care/ [Accessed 8 Oct 2018].

8 Marques MM, Alves E, Queirós C, et al. The effect of profession on burnout in hospital staff. Occup Med 2018;68:207-10.

9 Hayes B, Prihodova L, Walsh G, et al. What's up doc? A national cross-sectional study of psychological wellbeing of hospital doctors in Ireland. BMJ Open 2017;7:e018023.

10 Department of Health. A wide-angle international review of evidence and developments in mental health policy and practice. Dublin: Work Research Centre, 2017.

11 McNicholas F. Child \& Adolescent Emergency Mental Health Crisis: A Neglected Cohort. Ir Med J 2018;111:841.

12 Maslach C, Leiter MP. Understanding the burnout experience: recent research and its implications for psychiatry. World Psychiatry 2016;15:103-11.

13 von Elm E, Altman DG, Egger M, et al. The strengthening the reporting of observational studies in epidemiology (STROBE) statement: guidelines for reporting observational studies. Int J Surg 2014;12:1495-9.

14 Kristensen TS, Borritz M, Villadsen E, et al. The Copenhagen burnout inventory: a new tool for the assessment of burnout. Work \& Stress 2005;19:192-207.

15 Maslach C, Jackson SE. Maslach burnout Inventory-research edition. Palo Alto, CA: Consulting Psychologists Press, 1981.

16 Milfont TL, Denny S, Ameratunga S, et al. Burnout and wellbeing: testing the Copenhagen burnout inventory in New Zealand teachers. Soc Indic Res 2008;89:169-77.

17 Irish Department of Health \& Children.. A vision for change: report of the expert group on mental health policy. Dublin: Stationary Office, 2006.

18 Seanad Public Consultation Committee publishes report on children's mental health services, 2019. Available: https://www. oireachtas.ie/en/press-centre/news-and-features/20171018-seanadpublic-consultation-committee-publishes-report-on-children-smental-health-services/

19 Borritz M, Christensen KB, Bültmann U, et al. Impact of burnout and psychosocial work characteristics on future long-term sickness absence. prospective results of the Danish PUMA study among human service workers. J Occup Environ Med 2010;52:964-70. 
20 Chambers CNL, Frampton CMA, Barclay M, et al. Burnout prevalence in New Zealand's public hospital senior medical workforce: a cross-sectional mixed methods study. BMJ Open 2016;013947:e013947.

21 Creedy DK, Sidebotham M, Gamble J, et al. Prevalence of burnout, depression, anxiety and stress in Australian midwives: a crosssectional survey. BMC Pregnancy Childbirth 2017;17:13.

22 Margiotta F, Crudden G, Byrne D, et al. Prevalence and co-variates of burnout in consultant Hospital doctors: burnout in consultants in Ireland study (BICDIS). Ir J Med Sci 2019;188:355-64.

23 Howard R, Kirkley C, Baylis N. Personal resilience in psychiatrists: systematic review. BJPsych Bulletin 2019;43:209-15.

24 Jovanović N, Podlesek A, Volpe U, et al. Burnout syndrome among psychiatric trainees in 22 countries: risk increased by long working hours, lack of supervision, and psychiatry not being first career choice. Eur Psychiatry 2016;32:34-41.

25 Korkeila JA, Töyry S, Kumpulainen K, et al. Burnout and selfperceived health among Finnish psychiatrists and child psychiatrists: a national survey. Scand J Public Health 2003;31:85-91.

26 Mörelius E, Gustafsson PA, Ekberg K, et al. Neonatal intensive care and child psychiatry inpatient care: do different working conditions influence stress levels? Nurs Res Pract 2013;2013:1-8.

27 Jovanović N, Beezhold J, Tateno M, et al. Depression and suicidality among psychiatric residents - results from a multi-country study. $J$ Affect Disord 2019;249:192-8.

28 Walsh G, Hayes B, Freeney Y, et al. Doctor, how can we help you? qualitative interview study to identify key interventions to target burnout in hospital doctors. BMJ Open 2019;9:e030209.

29 Clarke R. Your life in my hands-a junior doctor's story. London: John Blake Publishing Ltd, 2017.

30 Irish Medical Organisation. IMO Submission to the HSE on the Review of the Child and Adolescent Mental Health Services(CAMHS) Standard Operating Procedure, 2018. Available: https://www.imo.ie/ policy-international-affair/documents/IMO-Sub-to-the-HSE-CAMHSSOP.pdf

31 Francis R. Report of the mid Staffordshire NHS Foundation trust public inquiry: Executive summary. London: The Stationery Office, 2013: 947.

32 Department of Health. Strategic review of medical training and career structure fourth progress report ("MacCraith Report”). Dublin, 2016.

33 Humphries N, Tyrrell E, McAleese S, et al. A cycle of brain gain, waste and drain - a qualitative study of non-EU migrant doctors in Ireland. Hum Resour Health 2013;11:63.

34 Humphries N, McAleese S, Tyrrell E, et al. Applying a typology of health worker migration to non-EU migrant doctors in Ireland. Hum Resour Health 2015;13.

35 Williams D, Thomas S. The impact of austerity on the health workforce policies in Ireland (2008-2014). Hum Resour Health 2017;15:017-230.
36 Brugha R, Cronin F, Clarke N. RCSI health workforce Research Group. retaining our doctors: medical workforce evidence, 2013-18. Dublin: Royal College of Surgeons in Ireland, 2018. https://epubs. rcsi.ie/ephmrep/13

37 Comhairle na nDochtuiri Leighis Medical Council. Back to PublicationsMedical workforce intelligence report 2015. A report on the annual registration retention survey, 2014. Available: https:// medicalcouncil.ie/News-and-Publications/Reports/MedicalWorkforce-Intelligence-Report-2015.html

38 Priebe S, Fakhoury WKH, Hoffmann K, et al. Morale and job perception of community mental health professionals in Berlin and London. Soc Psychiatry Psychiatr Epidemiol 2005;40:223-32.

39 Lunn B. Recruitment into psychiatry: an international challenge. Aust N Z J Psychiatry 2011;45:805-7.

40 Craddock N, Antebi D, Attenburrow M-J, et al. Wake-Up call for British psychiatry. Br J Psychiatry 2008;193:6-9.

41 Lambert TW, Smith F, Goldacre MJ. Career specialty choices of UK medical graduates of 2015 compared with earlier cohorts: questionnaire surveys. Postgrad Med J 2018;94:191-7.

42 Fazel S, Ebmeier KP. Specialty choice in UK junior doctors: is psychiatry the least popular specialty for UK and international medical graduates? BMC Med Educ 2009;9:77.

43 Katschnig $\mathrm{H}$. Are psychiatrists an endangered species? observations on internal and external challenges to the profession. World Psychiatry 2010;9:21-8.

44 West CP, Dyrbye LN, Erwin PJ, et al. Interventions to prevent and reduce physician burnout: a systematic review and meta-analysis. The Lancet 2016;388:2272-81.

45 West CP, Dyrbye LN, Shanafelt TD. Physician burnout: contributors, consequences and solutions. J Intern Med 2018;283:516-29.

46 Wallace JE, Lemaire JB, Ghali WA. Physician wellness: a missing quality indicator. The Lancet 2009;374:1714-21.

47 Lemaire JB, Wallace JE. Burnout among doctors. BMJ 2017;358.

48 Smith PC, Brown Levey SM, Lyon C. Evaluating transformation with available resources: the influence of apex on depression screening. Fam Syst Health 2017;35:238-47.

49 Taylor C, Xyrichis A, Leamy MC, et al. Can Schwartz center rounds support healthcare staff with emotional challenges at work, and how do they compare with other interventions aimed at providing similar support? A systematic review and scoping reviews. BMJ Open 2018;8:e024254.

50 George MS. Stress in NHS staff triggers defensive inward-focussing and an associated loss of connection with colleagues: this is reversed by Schwartz rounds. J Compassionate Health Care 2016;3.

51 Cunningham J, Bates U, Tracey G, et al. Who cares for the carers? Schwartz rounds: a first in Ireland. Psychoncology 2016;25:147-8.

52 Balint M. The doctor, his patient and the illness. Millennium. Edinburgh: Churchill Livingstone, 2000. 